\title{
SOME REMARKS ON THE RECESSION OPERATION FOR SQUINT
}

BY

\author{
J. G. Milner \\ LON DON
}

Introduction. In this paper I shall endeavour to show the value $\vec{\circ}$ of the operation of recession of the internal rectus for convergent $\overrightarrow{ }$ concomitant squint. The question is discussed entirely from the operative side. A short description of a simple technique for $\frac{0}{0}$. recession is given, and the results of a series of fifty cases is compared with a number of cases operated upon at the Royal ${ }_{\infty}^{\circ}$ Westminster Ophthalmic Hospital by other methods, and by several surgeons.

\section{Statistical}

Only cases are included in which the operation under considera-c tion was the first to be performed on the particular patient.

Between 1929 and 19:32, among other operations for squint, there were performed :-

Combined tenotomy and advancement $\quad \ldots \quad 221$ cases

$\begin{array}{llllll}\text { Advancement } \ldots & \ldots & \ldots & \ldots & \ldots & 32 \text { cases } \\ \end{array}$

$\begin{array}{llllll}\text { Free tenotomy } \ldots & \ldots & \ldots & \ldots & \ldots & 28 \text { cases }\end{array}$

Owing to insufficient data of 40 cases of the combined operations these have been excluded, and the free tenotomy cases are separated $\stackrel{\mathbb{Q}}{\stackrel{2}{ }}$ into divergent cases and convergent cases, because the results are $\overrightarrow{\overrightarrow{0}}$ very different. We have, therefore, for consideration :-

Combined tenotomy and advancement $\ldots \quad 181$ cases

$\begin{array}{lllllll}\text { Advancement } & \ldots & \ldots & \ldots & \ldots & \ldots & 32 \text { cases }\end{array}$

Tenotomy (for convergent strabismus) $\quad \ldots \quad 16$ cases

Tenotomy (for divergent strabismus) $\quad \ldots \quad 12$ cases

and the results are shown in the following table:-

TABLE I

\begin{tabular}{cr|r|c|c|c} 
Operation & $\begin{array}{r}\text { Total } \\
\text { cases }\end{array}$ & Straight & Not straight & Percentage & $\begin{array}{c}\text { Average angle } \\
\text { of reduction }\end{array}$ \\
\hline $\begin{array}{c}\text { Combined tenotomy } \\
\text { and advancement }-181\end{array}$ & 99 & 82 & $54.7 \%$ & $23^{\circ}$ \\
Advancement - - & 32 & 9 & 23 & $28 \%$ & $10^{\circ}$ \\
Free tenotomy C. -16 & 4 & 12 & $25 \%$ & $10^{\circ}$ \\
Free tenotomy D. - & 12 & 10 & 2 & $83.3 \%$ & $15^{\circ}$ \\
\hline
\end{tabular}


In compiling these figures I have regarded $5^{\circ}$ of squint as cosmetically straight. The angles of squint were taken from the notes of each case. (In the recession series given below all angles were measured on the synoptophore).

From this table several interesting points can be noted. First, in the combined operation, only $54 \cdot 7$ per cent. were straight, which means that $45 \cdot 3$ per cent. required a further operation. Second, advancement by itself has little hope of success, and third, a free tenotomy for divergent squint appears to be very satisfactory. Admittedly the last two observations are based on very few cases, but it will not be out of place here to discuss these points more fully.

Consider an advancement as an original operation. This, to my mind, is a thoroughly unsound procedure. The muscle to be advanced is nearly always a thin weak band, with its fibres stretched, a contrast to its antagonist, which is usually a hypertrophied fleshy muscle. In the operation of advancement this attenuated muscle is detached from its insertion and re-attached further forward. Instead of tending to rotate the eye towards itself, and thereby correct the squint, it seems to me more likely that the muscle will stretch still further, and the eye remain convergent. Furthermore, in this operation, acting against the advanced muscle is its powerful antagonist, tending all the time to minimize the effects of the operation. It is not surprising to me, therefore, that there is a low percentage of successful results, and that the average angle of reduction is only $10^{\circ}$.

With regard to free tenotomy; these figures are too small to be of any value at all, but all we learn is that in divergent squint there is a good chance of success. I think most ophthalmic surgeons have now given up a free tenotomy only, for convergent squint.

I have not yet had the opportunity of doing a recession in a divergent squint, but theoretically it is a better surgical operation than a free tenotomy. In a recession, the muscle is re-attached exactly where the surgeon wishes, and he can control the amount done. In a tenotomy, however, there is no knowing what will happen to the muscle in any given case, and there is no control over the angle of reduction. If the surgeon prefers tenotomy to recession, therefore, he should do a guarded tenotomy with a retaining suture, and I do not claim that a recession is any better than this.

In the following table are shown the results of my series of 50 recession operations performed between 1932 and 1934 . 


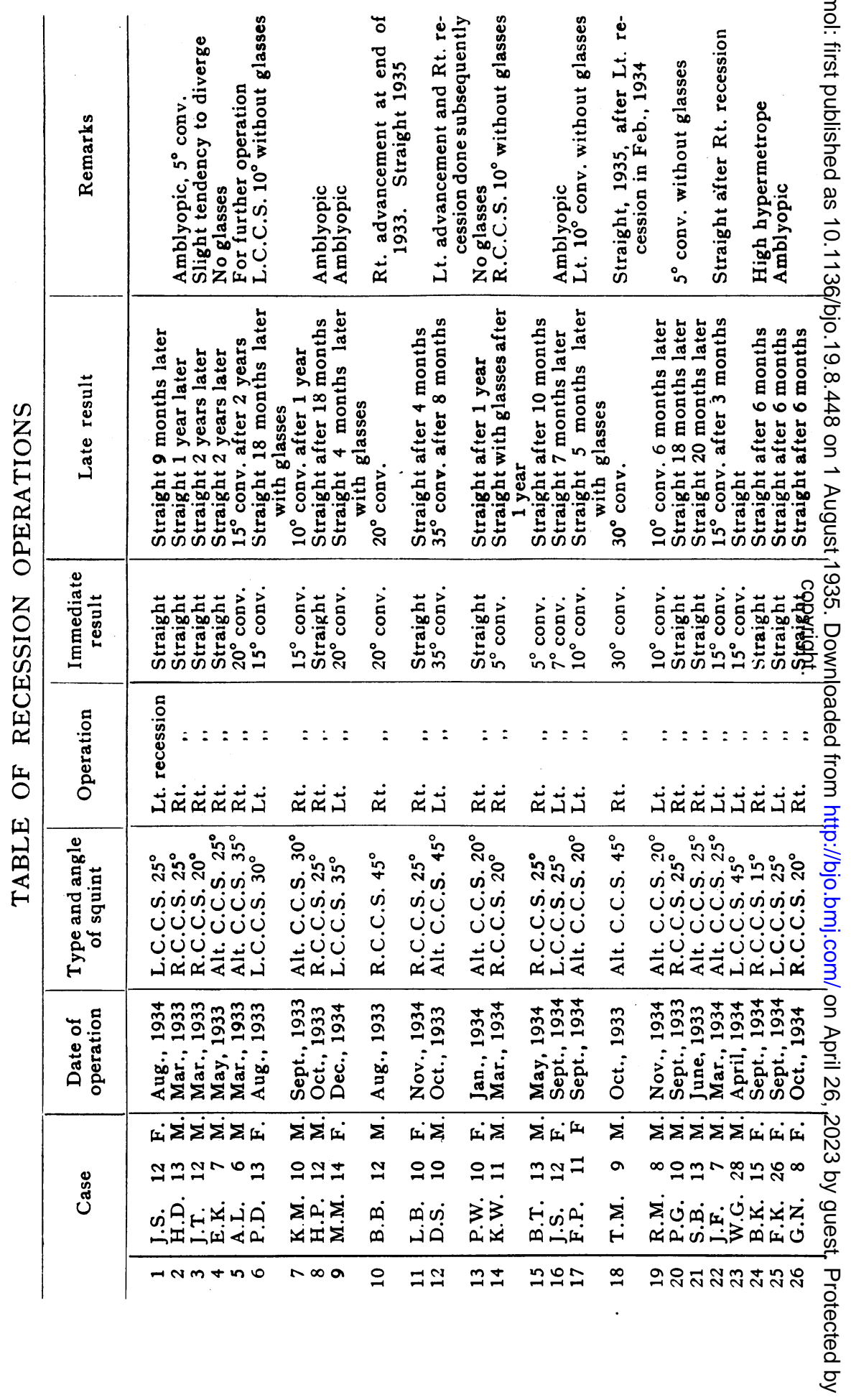


Recession Operation for SQUint

451

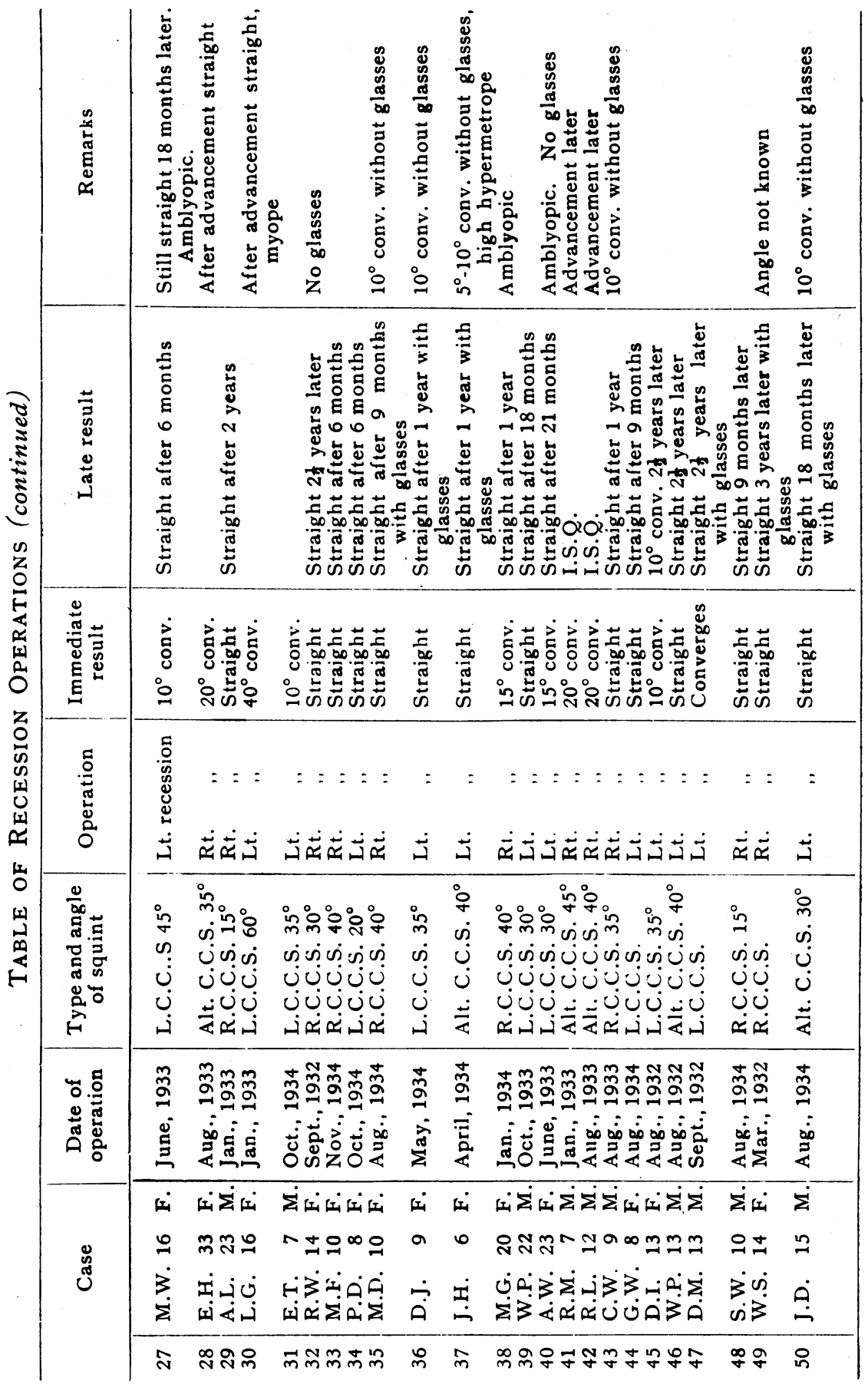


It will be seen that :-

1. 37 cases or 74 per cent. were cosmetically straight (here again $5^{\circ}$ convergence is regarded as straight) after periods varying from 3 months to 3 years.

2. 10 cases were straight only with glasses, converging about $10^{\circ}$ without glasses.

3 . The average angle of reduction was $24^{\circ}$.

4. Of the 13 cases not straight, 9 were alternating, and of these 9 the original angle of squint was $30^{\circ}$ or more, in 7 .

5. Cases 6, 7, 9, 17, 23, 27, 38, 40, immediately after operation were convergent $10^{\circ}$ or more, but that all these became less convergent later. (It should be made clear that the immediate result means the result at the time of the patient's discharge from hospital, ten days after the operation).

\section{Comments}

It seems justifiable to assert that the recession operation compares favourably with a combined tenotomy and advancement. The angle of reduction in the two tables is the same. In Table I the angles were taken from the notes, and were not all measured accurately. In Table II the angles were measured on the synoptophore. Anyo discrepancy here is, I think, in favour of the recession, becausee the tendency is to over-estimate angles of squint if they are judged by looking at them. The percentage of successful results is much? better with the recession (74 per cent. compared with 54.7 per cent.) but these figures are perhaps misleading owing to the difference in totals. In the recession operation only one muscle is disturbed, and this is surely an advantage.

I want now to refer to some criticisms of this operation.

First, it has been suggested that it is a dangerous operation because the sclera is so thin at the equator, and the eyeball is likely to be perforated by the needle. I am sure that there is no need for this accident; the sclera is admittedly very thin, but as there will be no tension on the sutures, it is not necessary to take a very firm grip, only a few scleral fibres need be picked up on the needle.

Second, in some cases results have not been good, and this I believe to be due to the fact that the muscle has not been recessed far enough back. I have on a few occasions seen the operation done and the muscle only moved 2 or 3 millimetres.

Third, it has been said that if the muscle is recessed to, or beyond, the equator, convergence is interfered with. I have not met this complication, and upon enquiry of the orthoptic department I have heard no instance of it.

Fourth, there is the obvious criticism that divergence is likely to occur after several years, as was seen in free tenotomies. My 
own experience only goes back a few years, but I have only seen one case (case 3 of my series) in which there is now a slight tendency to divergence. Foster Moore, who started doing recession operations about 8 years ago, kindly sent me a personal communication in which he says that he can recall no case of this sequela.

Fifth, sinking in of the caruncle has been described as a late complication of this operation. I can only say I have never seen it.

\section{Recession Operation}

The angle of squint is measured on the synoptophore previous to operation. If the patient is a child, evipan anaesthesia is used. This is a very satisfactory anaesthetic, and causes the minimum discomfort both to the patient and also to the surgeon, who is not hampered in any way by anaesthetic apparatus. (The reader should consult the paper by Lyle and Fenton on Evipan Anaesthesia in Ophthalmic Surgery).

The Operation. The speculum is inserted and a vertical incision made through the conjunctiva about $3 \mathrm{~mm}$. from the limbus. The conjunctiva is separated towards the plica, and it is a good plan at this stage to insert a silk stitch into the conjunctival flap on the inner side (plica) as this flap is sometimes difficult to find at the end of the operation, and also the silk can be used to retract the flap; a less damaging method than by forceps.

In freeing the conjunctiva care must be taken not to open the rectus sheath, otherwise there may be troublesome bleeding, or the raw surface so produced may form adhesions with the under surface of the conjunctiva, and so minimize the extent of the recession. A squint hook is passed under the rectus muscle, which is isolated, and the hook is then replaced by a Prince's forceps. I prefer the forceps with a sliding catch, and three teeth on one blade. The forceps is applied about $2 \mathrm{~mm}$. from the insertion of the muscle to the globe, and the muscle is next freed from its scleral insertion by cutting with scissors on the limbal side of the forceps, flush with the blade. Thus a small stump of tendinous insertion is left attached to the sclera, and this is used at a later stage for rotating the globe.

Before inserting sutures the operator must be certain that the muscle is quite free from its surroundings. Very often one finds bands of insertion to the sclera further back on the under surface of the muscle, and others on the upper surface of the muscle finding attachment to the under surface of the plica. These must all be divided.

For the sutures 000000 catgut is used. The needle used is an ordinary curved squint needle (split-eye). The sutures are inserted as shown in Fig. 1. The needle is passed from front to back of 


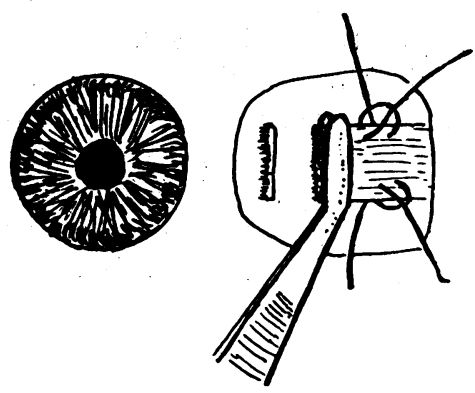

Fig. 1.

Sutures inserted through muscle, behind Prince's forceps.

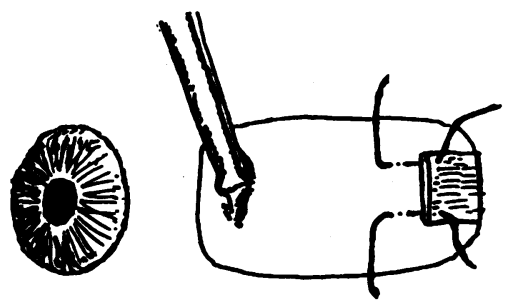

FIG. 2.

Sutures inserted through muscle and sclera.

the upper border of the muscle and passes again from front to back? A similar suture is inserted at the lower border of the muscle. The forceps is now removed. The globe is well rotated, a good grip being obtained by toothed forceps applied to the stump of original insertion.

The muscle is now re-attached to the sclera, the amount of recession depending on the angle of squint. The sclera is exceedingly thin in the region of the equator, so that care must be taken to avoid piercing it with the needle point. As there is no tension on the sutures, a firm grip is not necessary, consequently only a few scleral fibres need be picked up on the needle. The sutures are inserted in a line with the original insertion, and about $8 \mathrm{~mm}$. apart, so as to keep the muscle band flat. Finally the sutures are tied and cut short. The conjunctival incision is closed with two or three silk sutures. The catgut sutures are thus buried, and left to absorb, while the conjunctival sutures are removed in a week.

Post-operative. Both eyes are bandaged, and the child kept in bed for one week. At the end of this time the bandages are removed and the child gets up. Glasses are worn immediately, unless there is no refractive error. Twenty-four hours after operation the eyes are irrigated, and this is done once daily unless there is any necessity for more frequent treatment. The immediate post-operative result is not final. It may be some weeks before 
the end result is obtained. In cases, therefore, in which one recession is not enough to bring the eyes straight, I prefer to wait some weeks before doing a second operation.

When a second operation is necessary, either an advancement of the external rectus of the same eye, or a recession of the internal rectus of the other eye, is done. In this series four cases have had recession followed by advancement, and three of these were straight: the other had to have, as well, a recession on the other eye (Case 12). Two have had recession on each side, and these are straight. I am inclined to think that in an amblyopic eye it is better to do the second operation on this eye, and leave the good eye alone, but in an alternating squint a recession on both may be done.

With regard to the amount of recession, I do not believe it is worth while trying to work out how many millimetres of recession are equivalent to degrees of squint. Each case varies to some extent, and in any event, as is seen from several of the cases in Table II, the end result is not the same as the immediate result.

From Table II we see that the amount expected of a recession is about $25^{\circ}$, and in a squint of this size I endeavour to recess as far back as the equator; if the squint is more than $25^{\circ}$, I try and recess a little further back still, but usually the equator is as far as can conveniently be managed. If the squint is less than $25^{\circ}$, say $15^{\circ}$, then the muscle should be re-inserted just in front of the equator. It is useless to recess 2 or 3 millimetres. In fact, if we remember that 1 millimetre is left at the insertion, 2 millimetres are taken up by the forceps. (and we insert our stitches just behind this) and then we "recess" 3 millimetres, we are reallv re-attaching the muscle exactly where that part of it originally lay in contact with the sclera, and the result of the operation is nothing.

REFERENCE

Lyle and Fenton.-Brit. Med. Jl., Vol. II, p. 589, September 29, 1934.

\section{EXPERIENCES WITH GLAUCOSAN}

BY

Dr. CARL Hamburger

BERLIN

THE French Ophthalmologist Darier was the first to make the experiment (1896) of utilizing the hormone of the suprarenal gland for the purposes of ophthalmology.

His most important discovery, subsequently confirmed by general observations, was an enlargement of the pupil (sympathetic excitation) while reducing the eye pressure. Not until 20-30 